\title{
Fear of Death and the Symmetry Argument
}

\author{
Gal Yehezkel \\ The Sapir Academic College \\ Department of B.A. in Liberal Arts and Sciences \\ D.N. Hof Ashkelon 79165 \\ Sha'ar Hanegev \\ Israel \\ \& \\ The Open University of Israel \\ Department of History, Philosophy and Judaic Studies \\ The Dorotby de Rothschild Campus \\ 108 Ravutski Street \\ P. O. Box 808, Raanana 43107 \\ Israel \\ Yehezkel.G@gmail.com
}

Article info

CDD: 128.5

Received: 01.07.2016; Revised: 02.10.2016; Accepted: 07.11.2016

DOI: http://dx.doi.org/10.1590/0100-6045.2016.V39N4.GY

Keywords:

Deprivation Account

Fear of Death

Lucretius

Symmetry Argument

Time

\begin{abstract}
According to the Symmetry Argument against the fear of death, our attitudes towards birth and death should be identical. In this paper I defend the Deprivation Account of the badness of death, according to which death is bad because it deprives one of future goods. After rejecting previous attempts to explain and justify the asymmetry in our attitudes towards birth and death I argue that the asymmetry in our attitudes is both explained and justified by the fact that contrary to birth, death is not viewed as a nomologically necessary condition for life, and therefore death is viewed as an unnecessary limitation of life.
\end{abstract}

Manuscrito - Rev. Int. Fil. Campinas, v. 39, n. 4, pp. 279- 296, out.-dez. 2016. 
1.

In an attempt to dispel the fear of death Lucretius suggests that we should:

Look back now and consider how the bygone ages of eternity that elapsed before our birth were nothing to us. Here, then, is a mirror in which nature shows us the time to come after our death. Do you see anything fearful in it?

(Lucretius, bk III, vv. 972-75)

Lucretius turns our attention in this passage to a puzzling asymmetry in our attitudes towards our prenatal nonexistence and our posthumous nonexistence. While in each of these periods of time we do not exist, we normally fear our later limit of life, that is, death, but share no similar feeling towards our earlier limit of life, that is, birth. (I ignore in this context the fact that life actually begins before birth, for it has no significance for the present discussion. Obviously, due to the difficulty of determining when human life does begin, birth was always a natural choice for marking the beginning of life).

Lucretius' observation forms the basis for the Symmetry Argument against the fear of death. The argument suggests that given the symmetry between the two temporal limits of our existence, our attitudes towards our birth and death should also be symmetrical. Since there is nothing frightening in the earlier temporal limit of our existence, we should also not fear the later temporal limit of our existence.

Notwithstanding the obvious benefit of dispelling the fear of death, many philosophers found this argument wanting, and attempted to defend the rationality of our common sense attitudes towards the temporal limits of our existence. Any such defence requires the establishment of the badness of death, thus justifying our fear of death, assuming that fear of bad things is rational (see, for example, Aristotle 2004, 1115a). Furthermore, any successful defence of our normal attitudes towards the temporal limits of our existence should also explain and justify the asymmetry in our attitudes. That is, it should indicate a relevant asymmetry between the earlier and the later temporal limits of our life, such as would explain and justify our lack of fear of birth.

Manuscrito - Rev. Int. Fil. Campinas, v. 39, n. 4, pp. 279- 296, out.-dez. 2016. 
In this paper I adopt a version of the Deprivation Account of the badness of death. The Deprivation Account originates from Nagel, who suggested that death is bad because it deprives one of future goods (for example, pleasures) which one could enjoy if one died later (1970, p. 75).

Notwithstanding the attractiveness of this explanation of the badness of death, it leaves unanswered the question of the asymmetry between birth and death. Moreover, it seems that an analogous consideration applies to birth. For it can be argued that birth equally deprives one of past goods, which one could have enjoyed if one was born earlier.

My purpose in this paper is to defend the Deprivation Account of the badness of death. I do so by supplementing Nagel's account with an explanation of the generally accepted asymmetry between birth and death, which justifies the asymmetry in our attitudes.

I begin by arguing (in section 2) that while the Deprivation Account of the badness of death is a truism, previous attempts to identify the relevant asymmetry between birth and death failed to justify the asymmetry in our attitudes. I pay particular attention to the influential attempt of Brueckner and Fischer (1986) to explain the asymmetry in our attitudes towards birth and death based on an asymmetry in our attitudes towards past and future pleasant experiences. In section 3 I examine any attempt to establish the asymmetry between birth and death based on metaphysical considerations as to the direction of time. I argue that the metaphysics of time is unable to account for the asymmetry in our attitudes towards the temporal limits of our existence. In section 4 I present my contribution to the Deprivation Account of the badness of death. I argue that the asymmetry in our attitudes is both explained and justified by generally accepted contingent facts about the development of (human) life. More specifically, I argue that the asymmetry in our attitudes is both explained and justified by the view that contrary to birth, death is not a nomologically necessary condition for life, and therefore death is viewed as an unnecessary limitation of life. In section 5 I summarize and conclude my paper.

Manuscrito - Rev. Int. Fil. Campinas, v. 39, n. 4, pp. 279- 296, out.-dez. 2016. 
2.

The Deprivation Account's answer to the Symmetry Argument is based on two claims. The first claim is that death is bad because it deprives one of future goods. The second is that there is a relevant asymmetry between the past and the future, which explains and justifies the asymmetry in our attitudes towards birth and death. The major disagreement found among philosophers who adopt the Deprivation Account is about the nature of this asymmetry.

To begin with the first claim, assuming that the possibility of an afterlife is rejected, this proposition is not only true, but correctly interpreted is in fact a truism. Death is bad not because of any inconvenience which may be involved in the process of dying - we find death bad even if it is quick and painless. Nor is it bad because of any negative property of being dead - death per se has no value (Nagel 1970, pp. 73-4). We find death bad because we want to persist in our lives, that is, to live more. If one wants something, it is because one sees something good about it, either intrinsically or instrumentally, that as, as a means to an end which is perceived to be good (Aristotle 2004, 1094a). Hence, we want to live more because we find something good in life, either as a means to achieve other goods, or simply because we find a value in life per se. We therefore view death as bad because it deprives us of future goods. This is the reason why in some extreme circumstances, for example euthanasia, death can be seen as a blessing. If one can expects nothing more of life but pain and misery, death can be seen as something good.

The truism that we find death bad because it deprives us of future goods is however insufficient in itself to provide an answer to the Symmetry Argument. For the considerations which were used to explain and justify the badness of death apply equally to birth. Both birth and death mark the limits of our temporal existence. Both our prenatal nonexistence and our posthumous nonexistence seem bad, because they deprive us of the goods we might have enjoyed had we lived in these periods of time. If death is bad because it deprives us of goods which we would have enjoyed if our lives had ended later, birth should be viewed negatively because it deprives us of goods which we might have enjoyed if our lives had begun earlier.

If one wants to justify our asymmetrical attitudes towards the temporal limits of our life, one must therefore indicate a relevant asymmetry between

Manuscrito - Rev. Int. Fil. Campinas, v. 39, n. 4, pp. 279- 296, out.-dez. 2016. 
birth and death, which can justify both our fear of death and our joy regarding birth.

There have been several attempts to indicate the asymmetry between death and birth which justifies the asymmetry in our attitudes. Nagel, for example, has argued against the claim that we could have existed earlier, thus rejecting the claim that it is better to be born earlier. According to Nagel, it is impossible for one to be born substantially earlier than one actually was, because the time of one's birth is essential for one's self-identity. Any possible person who would have been born substantially earlier than one actually was born would have been someone else (1970, p. 79).

Nagel's explanation for the asymmetry in our attitudes raises a difficulty. Nagel relies on an alleged asymmetry between the past and the future. For his explanation relies on the assumption that while it is impossible for one to be born earlier than one actually was, it is possible for one to die substantially later than one actually dies. However, the asymmetry between the past and the future is exactly what is under dispute here (Rosenbaum 1989, p. 361).

There have been attempts to defend Nagel's claim that one could not have been born earlier than one actually was (see, for example, Kaufman 1996; 1999; Belshaw 2000, McMahan 2006). However, these attempts have themselves been criticized (see, for example, Johansson 2008). I will not press this point further; the metaphysical thesis that one's identity depends on one's time of birth, even if it is correct, is too intricate and controversial to account for the common sense intuitive asymmetry between birth and death. Any viable explanation for the asymmetry in our attitudes must be at least as obvious and widely accepted as the attitudes it seeks to explain (for a similar claim, see Brueckner and Fischer 1986, p. 215). For in order to justify the asymmetry in our attitudes, any account should first and foremost explain the asymmetry in our attitudes.

Another suggested asymmetry between birth and death relates to an alleged asymmetry between the way we view early birth and the way we view late death. While we think of late death we naturally hold the birth date constant, and therefore think of a longer life. On the other hand, when we think of early birth, we do not think of a longer life span, because we do not hold the death date constant (Feldman 1991, pp. 222-3).

Again, this explanation raised several objections. For example, it has been argued that there are possible circumstances in which a person would have

Manuscrito - Rev. Int. Fil. Campinas, v. 39, n. 4, pp. 279- 296, out.-der. 2016. 
lived longer had he been born earlier (see, for example, McMahan 2006, pp. 216-17). However, envisioning special circumstances cannot discredit this suggested explanation for the way we normally think about birth and death, which admits of no special circumstances. Often our ordinary attitudes are strongly challenged by envisaging special circumstances, simply because we normally do not consider these possibilities. However, it is difficult to see how envisaging special circumstances can discredit an attempted explanation for the way we normally think, for the very same reason that we normally do not consider these special circumstances. A more convincing objection is raised by the question of whether it is normally justified to think of late death as a longer life span while not thinking the same about earlier birth. Unless we find an explanation which would justify this asymmetry in the way we think of early birth and late death, any attempt to rely on this asymmetry in order to answer the Symmetry Argument is begging the question.

An influential explanation for the asymmetry between the past and the future, which allegedly justifies the asymmetry in our attitudes towards the temporal limits of our existence, was first offered by Derek Parfit (1984), and later developed by Anthony Brueckner and John Martin Fischer (1986). In order to explain the asymmetry in our attitudes towards the temporal limits of our life, they rely on an asymmetry in our attitudes towards events which take place in our life. This asymmetry is reflected, for example, by the fact that we generally fear future pains, but are grateful for their passing (see, for example, Prior 1959). Generally speaking, and leaving aside special circumstances, we are usually more concerned about future bad events than about past bad events, and would prefer to be after an unpleasant event rather that before it.

Based on this asymmetry, Parfit has suggested that we are indifferent to our past suffering while not indifferent towards our future suffering, and that this asymmetry is not irrational (1984, pp. 165-185). This shows, according to Parfit, that it is not irrational to have different attitudes towards past and future bad events. Hence, death can be rationally considered by us to be a bad event, while birth is not.

Brueckner and Fischer have pointed out that even if Parfit is correct in claiming that it is not irrational to have asymmetrical attitudes towards symmetrical events in the past and in the future, his claim cannot be extended to the case of death. This is due to the fact that Parfit relies on examples in

Manuscrito - Rev. Int. Fil. Campinas, v. 39, n. 4, pp. 279- 296, out.-dez. 2016. 
which things are experienced as bad by the subject, while death is not experienced at all. Furthermore, it seems plausible to assume that Parfit's conclusion only applies to things which are experienced as bad by the subject (Brueckner and Fischer 1986, p. 216).

Brueckner and Fischer have suggested instead that the asymmetry in our attitudes towards prenatal and posthumous nonexistence is explained by the asymmetry in our attitudes toward good events, rather than the asymmetry in our attitudes toward bad events (1986, p. 219). The asymmetry in our attitudes towards good events in our life is the mirror image of the symmetry in our attitudes towards bad events. It is reflected, for example, in our preference to be before a pleasurable event rather than after it. Our attitude towards death is thus explained, according to this suggestion, by the fact that death deprives us of future experienced goods, which we look forward to and care about, while birth deprives us of past experienced goods, to which we are indifferent.

I find two major difficulties with Brueckner and Fischer's account of the fear of death. To begin with, the claim that we are indifferent to past goods is wrong. While it is true that we care more about future good events than we do about past good events, we do in fact care about past good events, just as we care about past bad events. For example, we would indeed prefer, given the choice, to be before a pleasurable event rather than after it. However, given a choice, we would also prefer a pleasurable past to an unpleasant past, or even to an indifferent past.

The latter claim can be illustrated using a variant of Parfit's hospital case (1985, pp. 165-6). Consider the following scenario: You visit a psychologist. She inquires about your childhood, but you are unable to remember whether you had a good childhood, a bad childhood or an indifferent childhood. However, if she asks you what kind of childhood you would prefer, I think it is obvious that most of us, if not all of us, would have preferred a good childhood.

We are therefore not indifferent to past good events, although we are more concerned about future good events than we are about past good events. Hence, although Brueckner and Fischer's account of our fear of death can explain why we view our death negatively, it fails to account for the fact that we view our birth positively. If Brueckner and Fischer's account was correct, we should have viewed our birth negatively, although less negatively than our death.

Manuscrito - Rev. Int. Fil. Campinas, v. 39, n. 4, pp. 279- 296, out.-dez. 2016. 
Finally, both Parfit's and Brueckner and Fischer's accounts of the fear of death fail on another, more basic, level. Parfit attempts to explain and justify the asymmetry in our attitudes towards the temporal limits of our existence by relying on the asymmetry in our attitudes towards bad events in our life. Brueckner and Fischer suggest instead that the asymmetry in our attitudes towards the temporal limits of our existence is explained and justified by the asymmetry in our attitudes towards good events in our life. However, Parfit, and Brueckner and Fischer following him, fail to explain and justify the asymmetry in our attitudes towards good and bad events in our life. Surely, if the asymmetry in our attitudes towards birth and death is called into question, the asymmetry in our attitudes towards events in our lives is also suspect, and hence any attempt to rely on the latter asymmetry in order to justify the former would beg the question. .

\section{3.}

Following the failure of previous attempts to defend the asymmetry in our attitudes towards the temporal limits of our existence, I wish to further examine the suggestion that the explanation for this asymmetry lies in the metaphysics of time. Le Poidevin, for example, has suggested that a rejection of the A-theory of time, which supposedly describes the common sense view of time, and adoption of the rival B-theory of time, will dispel our fear of death (1996, pp. 145-6). This suggestion implies that the A-theory of time, which maintains that the 'flow of time,' that is, the change in the determinations of past, present, and future, is an objective feature of reality, which constitutes the direction of time, is somehow able to explain and justify our fear of death.

Notwithstanding its prima facie attractiveness, any attempt to rely on the Atheory of time in order to justify the asymmetry in our attitudes raises difficulties.

Elsewhere I have argued that the different theories of time are irrelevant for explaining the asymmetry in our attitudes, both towards events in our life and towards the temporal limits of our existence (Yehezkel 2014). In the present context I wish to focus on the inability of the A-theory of time to

Manuscrito - Rev. Int. Fil. Campinas, v. 39, n. 4, pp. 279- 296, out.-dez. 2016. 
explain and justify the asymmetry in our attitudes towards birth and death, and therefore also its inability to explain and justify our fear of death.

If the A-theory of time can explain and justify the fact that we fear our death but celebrate our birthdays it can only be due to its adherence to the objectivity of the change in the determinations of past, present, and future, which allegedly constitutes the 'flow of time.' The change in these determinations marks a fundamental asymmetry between the past and the future, which is constituted by the direction of the moving present, from the past to the future - events in our lives are first future events, then they become present events, and finally they become past events.

Can this change in the determinations of past, present, and future per se explain why we fear death but not birth? Sometimes it is suggested that, in light of the direction of the moving present, from the past to the future, there a sense in which we can be said to 'approach' our death, while draw away from our birth. However, it is not easy to give meaning to this use of the term 'approach,' in light of the fact that both death and birth are part of our history. It seems that what is meant by this phrase that that our death is coming closer to the present, the moment in which it would become real. However, this cannot explain the asymmetry in our attitude towards birth and death, because we view birth as positive even if it is in the future (we look forward for the birth of our children, for example). Furthermore, both events are part of one's history, and if both are unavoidable (I shall consider the possibility that future events are undetermined below), I see no reason why one should adopt difference attitude towards birth and death.It might be argued that if time flows from the past to the future, then the different temporal limits of our life have a radically different significance. Birth marks the transition from nonexistence, which is bad, to existence, which is good, and therefore birth is a good event. Death on the other hand marks the transition from existence, which is good, to nonexistence, which is bad, and therefore death is a bad event.

Notwithstanding the attractiveness of this explanation, it is unsatisfactory in itself to justify the asymmetry in our attitudes. For comparison, think of a child who claims that one of the sides of the candy he is eating is good and the other is bad, for one of them marks the transition from not eating a candy to eating a candy, which is good, while the other marks the change from eating a candy to not eating a candy, which is bad. Furthermore, consider the

Manuscrito - Rev. Int. Fil. Campinas, v. 39, n. 4, pp. 279- 296, out.-dez. 2016. 
absurdity of mourning that fact that the candy is not longer, but only on one side of the candy - the bad side.

If the change in the determinations of the past, present and future can explain the asymmetry in our attitudes it can only be by constituting a fundamental ontological asymmetry between the past and the future. This is suggested for example by the Growing Block Theory, according to which only past and present events are real (or, exist simpliciter) while future events are not real (or, do not exist simpliciter).

However, this ontological symmetry seems unable to justify the asymmetry in our attitudes. For why should we be afraid of the later limit of our existence, which is not real, while being happy with the earlier limit of our existence, which is real? Prima facie, it is real events that should bother us, rather than unreal events, and therefore we should be more concerned with the past limit of our existence rather than the future limit of our existence.

This consideration leads us to another suggestion for explaining the asymmetry in our attitudes. According to this suggestion, the explanation for the asymmetry in our attitudes is found in the alleged asymmetry in the determinacy of past and future events. According to this asymmetry, while past events are determined, future events are undetermined.

Again, it might be argued against this suggestion that we should be more concerned about determined bad events rather than undetermined bad events. However, is it possible to supplement this suggestion with an explanation of why we should in fact fear undetermined bad events rather than determined bad events. According to this explanation, there is no point in having negative feelings towards determined bad events, because they cannot be avoided. On the other hand, it is beneficial to have negative feelings towards undetermined bad events, for these feelings serve as a motivation for attempting to avoid these events.

However, this suggestion fails to explain the asymmetry in our attitudes. For we are not indifferent to the limit of our existence in the past, as might be expected from this explanation. We celebrate birthdays, while according to this explanation we should view them as unavoidable bad, and therefore sad, events. Moreover, this suggestion fails to explain and justify our positive feelings towards the beginning of life even when it is in the future, for example when we are waiting for a forthcoming birth of a child. Similarly, it fails to explain and justify the negative feelings we have towards the end of life even

Manuscrito - Rev. Int. Fil. Campinas, v. 39, n. 4, pp. 279- 296, out.-dez. 2016. 
when it is in the past, for example after the passing of a parent. If this explanation had been correct, it would have been expected that our attitudes towards the temporal limits of our existence would change in time. That is, we would have viewed a future undetermined beginning of life in a negative light, just as we view the future undetermined end of life; and similarly we would have viewed the past determined end of life in a positive light, just as we view the past determined beginning of life.

In response to this objection, it might be agreed that the determinacy of the past per se does not explain the asymmetry in our attitudes. What is relevant is that the future depends on our intentions and actions, while the past is independent of our intentions and actions. Hence, it is beneficial, and therefore rational, to have negative feelings towards the later limit of our existence, while it is futile, and therefore irrational, to have negative feelings towards the earlier limit of our existence. It is rational to have negative feelings towards what we can influence, because our feelings are the trigger for our attempts to delay or even avoid death, but it is irrational to have negative feelings towards what cannot be influenced by us, that is, birth.

Again, this suggestion fails to address the asymmetry in our attitudes. For we have negative feelings towards death even if it is in the past, and positive feelings towards birth even if it is in the future. If we should fear a future death because it is beneficial, that is, as a motivation for attempting to postpone this death, surely it is beneficial to fear past birth, as a motivation for attempting to bring forward this birth.

The following discussion highlights what seems to be a general flaw in any attempt to rely on the metaphysics of time in order to provide an explanation for the asymmetry in our attitudes towards the temporal limits of our existence. Such attempts are based on the idea that time has a direction, which constitutes a symmetry between the past and the future.

The direction of time is supposed not only to explain the asymmetry in our attitudes towards the temporal limits of our existence, but also to explain its contrast to our attitudes to the spatial limits of our existence. I am not afraid to approach the northern limit of my existence, that is, the most northern point on earth which I shall visit, nor do I find anything happy about the southern limit of my existence, that is, the most southern point on earth which I shall visit.

Manuscrito - Rev. Int. Fil. Campinas, v. 39, n. 4, pp. 279- 296, out.-der. 2016. 
The attempts to explain and justify the disanalogy in our attitudes towards the spatial and the temporal limits of our existence, based on the metaphysics of time, revolves around the idea that time, in contrast to space, has an internal direction. However, as was clearly shown in the previous discussion, any such attempt would fail to explain why we have different attitudes towards the temporal limits of human existence (of other people) while they are both in the past or both in the future.

Finally, any attempt to explain the asymmetry in our attitudes based on the metaphysics of time would not only have to rely on a controversial theory of time, it would also have to rely on an intricate metaphysical theory. Even if this theory coheres with the common sense view of time, it is doubtful whether it can be said to explain the common sense view of time, and hence to explain our fear of death, because it can hardly be expected of the 'man on the street' to understand its intricacies. Obviously, one can attempt to explain our fear of death by evolutionary considerations, which rely on this theory, and of which the subject need not be conscious. However, although in a sense it would make our fear of death rational objectively, it would fail to justify the common sense belief that we do in fact understand why death is bad while birth is good.

4.

As mentioned before, the Deprivation Account of the badness of death relies on two assumptions in order to answer the Symmetry Argument. The first assumption is that death is bad because it deprives one of future goods. The second assumption is that there is a relevant asymmetry between the past and the future which explains and justifies the asymmetry in our attitudes. In light of the failure to explain and justify our attitudes based on metaphysical considerations, I suggest that the answer to the puzzle which concerns us can be found in generally accepted beliefs about the development of living creatures in general and human beings in particular. According to these beliefs, and in contrast to birth, death is not a nomologically necessary condition for life, and therefore death is viewed as an unnecessary limitation of life.

Manuscrito - Rev. Int. Fil. Campinas, v. 39, n. 4, pp. 279- 296, out.-dez. 2016. 
In order to explain and justify the asymmetry in our attitudes we should first turn our attention to the common belief that human life must have a beginning. This is not a metaphysical (or logical) claim about existence in general, according to which there must be a past time in which a human being does not exist, but rather a belief in a contingent biological fact, according to which any human being must undergo a biological process, such as natural conception and birth, by which this complex biological creature is created. Perhaps it is metaphysically (and logically) possible for something to exist without having a beginning in time. For example, some philosophers have argued that the universe has no beginning, and according to some interpreters Aristotle believed that species, including homo sapiens, has an infinite past (Lennox 2001, pp. 154-156). Obviously, the relevant idea for the current discussion is the idea of an infinite past of individuals, and indeed there are traditions which believe in reincarnation, and in some versions of the doctrine, there are infinitely many past incarnations. Whether this belief is true or not, it is not common or sufficiently justified, and thus irrelevant for explaining and justifying our prevalent attitudes. (Furthermore, if this belief had reflected the natural and common way of perceiving human life, an asymmetry in our attitudes would be unlikely. For this belief, which is commonly accompanied with the belief in immortality, is usually entertained specifically in order to dispel our fear of death.)

Perhaps it is therefore metaphysically (and logically) possible for human beings to exist without having a beginning in time. However, we usually believe that (as a matter of contingent fact) the existence of human beings has a beginning in time, and we even find it hard to understand how a human being, as a biologically complex creature, could exist if it has not come into existence through some kind of biological process such as birth. In nature, as we know it, without relying on any specific scientific theory, living creatures come to life through a complicated biological process.

In ancient times the process by which human beings come to life was familiar via the natural terms of conception, pregnancy, and birth. In modern times, in which life can be created in labs by artificial insemination, it is described in terms of an egg being fertilized and thus beginning a process of development, which is completed somewhere in the late second decade of human life. Birth, perhaps the most prominent point in this process, simply marks the success of a critical stage in this process, and is therefore

Manuscrito - Rev. Int. Fil. Campinas, v. 39, n. 4, pp. 279- 296, out.-dez. 2016. 
memorable. Any living human being has gone through at least part of this process, and completed this process if it reached adulthood. If this process is somehow disturbed, the consequences can be severe, and may include intense suffering and early death.

The most basic truism that follows from this description, known for millennia, is that having a beginning is a nomologically necessary condition for life. We simply cannot imagine a human life that has no beginning. Furthermore, although it is possible to envisage the creation of a human being who has not undergone birth as we know it, we must think of this creature as created in some way, perhaps in a scientifically fictional process in which individual atoms are connected together. What we cannot envisage is that this creature was never created. This is also true of other biological creatures, such as trees.

Given that we value life, it is now clear why we view the beginning of life as a favorable event. We are happy about the beginning of life because we think that life cannot exist without having a beginning, which would explain how such a complex phenomenon exists.

Let us now turn our attention to the later limit of life. Allegedly, all human lives must come to an end, not because of any metaphysical necessity, but as a matter of contingent fact, which we learn from our experience. All human beings are mortal, and their lives come to an end at one point or another. However, in contrast to birth, this contingent fact seems nomologically unnecessary and therefore avoidable. To begin with, although the biological process which marks the beginning of life is similar in all human beings, the processes which put an end to human lives are different from person to person. Some die due to grave bodily harm, others die from various diseases, and there are those who die from general deterioration caused by old age. While the process of growing up is rigid and repeats itself in every human being (if successful), no process of dying is a nomologically necessary condition for a human life. Indeed, it is easy to imagine a possible continuation of any human life, simply by imagining the absence of any disease or bodily harm which might bring this life to an end, or by imagining that the process of deterioration which is associated with old age is slowed down or even completely stopped.

In order to explain and justify our fear of death, and the asymmetry between birth and death, any explanation should first describe the way we

Manuscrito - Rev. Int. Fil. Campinas, v. 39, n. 4, pp. 279- 296, out.-dez. 2016. 
actually view birth and death. I believe that the account I have given accurately describes the way we generally think about human beings, or indeed about living creatures in general, as creatures that must have a beginning but not necessarily an end. We have no difficulty in accepting the idea that some creatures can potentially live forever, such as the Turritopsis nutricula, which is sometimes called the Immortal 'jellyfish,' and this possibility can be easily explained. However, we fail to understand the suggestion that this jellyfish exists without ever beginning to exist.

In order to justify our fear of death I argue in what follows that this alleged asymmetry between birth and death implies that birth is a positive event while death is a negative event. I shall not attempt, in the scope of this paper, to defend the belief that, contrary to death, birth is a nomologically necessary condition for life. Obviously, such a claim must be supported by biological or physical theories (perhaps based on the second law of thermodynamics), rather than by philosophical considerations (or else it would not involve a nomological necessity), and hence extends beyond the scope of this paper. For our present purposes I am content with the seeming reasonability of this claim and its general acceptance, as well as its coherence with scientific biological practices. This is reflected, for example, in the continual search for life forms that can possibly never die, but not for life forms that are possibly never born, as well as in the continuing attempt to explain the origin of life and the refusal to accept life as a phenomenon that simply has no beginning.

This view of life, which reflects the common sense view, marks a fundamental asymmetry between the beginning of life and its ending. While the earlier limit of our life is viewed as a nomologically necessary condition for life, the later limit of life is not a nomologically necessary condition for life, and is therefore an unnecessary limitation of life. The fear of death is therefore a fear of an arbitrary and possibly avoidable limit of life.

Given that we want to live longer, this view of human life places constraints on the way our wish may be fulfilled. Simply being born earlier, other things being equal, does not guarantee a longer life, for one might simply die ten year earlier than due. Similarly, the mere wish to die ten years later than one's actual death may be fulfilled without extending one's life, simply by being born ten years later than one's actual birth.

Our wish is to live a long life, and this can be achieved by manipulating the contingent factors which determine the human lifespan, thus extending

Manuscrito - Rev. Int. Fil. Campinas, v. 39, n. 4, pp. 279- 296, out.-der. 2016. 
the time between birth and death. What we wish for is that the contingent facts which limit our life would allow us to live a long life, perhaps even an unlimited life. Given the fact that the process which is associated with birth seems biologically necessary for life, this wish is directed towards death, which is conceived as a biologically avoidable limit of life. Hence, any such wish would be reflected by a wish that death would occur later, rather than the wish that birth would have occurred earlier.

Notice that I do not argue that we can extend life only into the future, not into the past, so we dwell on the fact that death blocks the former. It is the other way around - given what we believe to be contingent biologicals facts about human life, we focus our attention about death and on the possibility of extending life into the future. Death is not bad insofar as it deprives us of future goods that we would have received had we died later. In this respect, there is a perfect symmetry between birth and death. For being born no earlier than one was in fact born is not a nomologically necessary condition for life. Death is bad not because of its timing, but because its occurrence is not a nomologically necessary condition for life, while the occurrence of birth is a nomologically necessary condition for life. That is, Death is bad because its occurrence deprives us of future goods which we would have received had we not died at all. The same cannot be said about birth, because birth is conceived to be a nomologically necessary condition for life.

This observation also explains and justifies the asymmetry in our attitudes towards birth and death even when they are both in the future or both in the past. We are happy with the forthcoming birth, which is conceived to be a nomologically necessary condition for life, and only worry that the process might somehow go astray. We see death, on the other hand, as a nomologically unnecessary process, which merely limits what we value and wish for more, that is, life, and thus deprives us of future goods.

\section{5.}

The Symmetry Argument challenges the asymmetry in our attitudes towards birth and death, as the temporal limits of life. In hope of defusing our fear of death, the Symmetry Argument turns our attention to the fact that far from having negative feelings towards the earlier limit of our life, we view

Manuscrito - Rev. Int. Fil. Campinas, v. 39, n. 4, pp. 279- 296, out.-dez. 2016. 
birth as a happy occasion. If our asymmetric attitudes towards the temporal limits of our existence are to be explained and justified, a relevant asymmetry between birth and death must be identified.

The answer to the Symmetry Argument is not found in the metaphysics of time, but rather in a reminder of some of the contingent facts, or what we believe to be facts, that are associated with the temporal limits of life. I have not attempted to defend this common belief - a task that falls beyond the scope of this paper. Rather, I have argued that given this belief the asymmetry in our attitude towards the limits of our existence in time is justified. Obviously, if this belief is found to be false, the asymmetry in our attitude loses its justification.

The relevant asymmetry between birth and death is thus found in our view of contingent facts about the biological processes that are associated with birth and death. While birth is viewed as a nomologically necessary condition for life, and therefore is seen as a blessing, death is viewed as a nomologically unnecessary, and therefore possibly avoidable, limit to life. This asymmetry not only explains the fear of death, and the joy of birth, but also justifies these basic human attitudes.

\section{References}

ARIsTOTLE. Nicomachean Ethics, Translated by Roger Crisp. Cambridge: Cambridge University Press, 2004.

YeHEZKEL, G. "Theories of Time and the Asymmetry in Human Attitudes". Ratio, 27(1), pp. 68-83, 2014.

BelshaW, C. "Later death/earlier birth". Midwest Studies in Philosophy, 24(1), pp. 69-83, 2000.

Brueckner, A. and Fischer, J. M. "Why is Death Bad?" Philosophical Studies, 50, pp. 213-221, 1986.

Feldman, F. "Some puzzles about the evil of death". Philosophical Review, 100(2), pp. 205-227, 1991.

Johansson, J. "Kaufman's response to Lucretius". Pacific Philosophical Quarterly, 89(4), pp. 470-485, 2008.

Manuscrito - Rev. Int. Fil. Campinas, v. 39, n. 4, pp. 279- 296, out.-dez. 2016. 
Kaufman, F. "Death and deprivation: Or why Lucretius' Symmetry Argument fails". Australasian Journal of Philosophy, 74(2), pp. 305-312, 1996.

"Pre-vital and post-mortem non-existence". American Philosophical Quarterly, 36(1), pp. 1-19, 1999.

LE Poidevin, R. Arguing for Atheism. London: Routledge, 1996.

Lennox, G. L. Aristotle's Philosophy of Biology: Studies in the Origins of Life Science. New York: Cambridge University Press, 2001.

LuCRETIUs. On The Nature Of Things. Translated by Martin Ferguson Smith. Cambridge: Hackett, 2001.

MCMAHAN, J. "The Lucretian argument". In K. McDaniel et al (Eds.) The good, the right, life and death: Essays in honor of Fred Feldman. Burlington: Ashgate Publishing, pp. 213-226, 2006.

NAgEL, T. "Death". Nous, 4(1), pp. 73-80, 1970.

PARFIT, D. Reasons and Persons. Oxford: Oxford University Press, 1984.

Prior, A. "Thank Goodness That's Over". Philosophy, 34, pp. 12-17, 1959.

Rosenbaum, S. "The Symmetry Argument: Lucretius against the fear of death". Philosophy and Phenomenological Research, 50(2), pp. 353-373, 1989.

Manuscrito - Rev. Int. Fil. Campinas, v. 39, n. 4, pp. 279- 296, out.-dez. 2016. 